\title{
MULTIATTRIBUTE DECISION MAKING PENENTUAN AKREDITASI SMA MENGGUNAKAN METODE ECKENRODE DAN DIA
}

\author{
Yeffriansjah Salim \\ STMIK Indonesia Banjarmasin \\ Jl. Pangeran Hidayatullah Banjarmasin, Telp. 081348000591 \\ Email : yeffri_salim@yahoo.com
}

\begin{abstract}
The accreditation of a high school education institution (SMA) has been carried out by BAN-SM of South Kalimantan Province in stages starting from the provincial level as a recommendation provided to the national level as the decision-maker for determining accreditation. The accreditation implementation process is carried out manually. This process is carried out by both assessors and secretariat staff in charge of receiving and checking accreditation documents and reporting document inspection results and real conditions in the field that often experience fatigue and missing data. These constraints can cause the accreditation process's objectivity and even the possibility of "wrong value" to overcome these problems. We need a tool used for the decision-making process. This study made a multi-attribute decision-making model in determining the accreditation of SMA using the Eckenrode and DIA methods. The Eckenrode method is used to calculate the weight value; DIA is used to rank alternative decisions. This research is a multi-attribute decisionmaking model in determining high school accreditation by testing 50 data samples, producing an average value of $95 \%$ accuracy, and a sensitivity value of $93 \%$. And specificity of $91 \%$.
\end{abstract}

Keywords: accreditation of SMA, Eckenrode, DIA

\begin{abstract}
Abstrak
Akreditasi suatu lembaga pendidikan sekolah menengah atas (SMA) selama ini dilaksanakan oleh BAN-SM Provinsi Kalimantan Selatan secara bertahap dimulai dari tingkat provinsi sebagai pemberi rekomendasi hinga ke tingkat nasional selaku pengambil keputusan penentuan akreditasi. proses pelaksanaan akreditasi dilaksanakan secara manual. Proses ini dilaksanakan oleh asesor maupun staf sekretariat yang bertugas menerima dan memeriksa dokumen akreditasi serta melaporkan hasil pemeriksaan dokumen dan kondisi riil di lapangan sering mengalami kendala seperti lelah, data yang hilang. Kendala-kendala tersebut dapat menjadi penyebab ketidakobjektifan proses akreditasi bahkan kemungkinan "salah nilai", untuk mengatasi permasalahan tersebut maka diperlukan suatu alat bantu yang digunakan untuk proses pengambilan keputusan. Penelitian ini membuat model multiatribute decision making dalam menentukan akredtasi SMA menggunakan metode Eckenrode dan DIA. Metode Eckenrode digunakan untuk
\end{abstract}


menghitung nilai bobot, DIA digunakan untuk perangkingan alternatif keputusan. Hasil dari penelitian ini adalah model multiatribute decision making dalam menentukan akredtasi SMA dengan pengujian menggunakan 50 sampel data dan menghasilkan nilai nilai rata-rata accuracy 95\%, nilai sensitivitas sebesar 93\%. dan spesifisitas 91\%.

Kata kunci: Akreditasi SMA, Eckenrode, DIA

\section{PENDAHULUAN}

Akreditasi merupakan proses penilaian secara komprehensif terhadap kelayakan pada lembaga pendidikan dan hasil tersebut diwujudkan dalam bentuk pengakuan dan peringkat peringkat akreditasi yang diterbitkan oleh lembaga akreditasi mandiri dan professional.

Berdasarkan UU Nomor 20 Tahun 2003 tentang Sistem Pendidikann Nasional Pasal 60 tentang Akreditasi menyatakan: Ayat (1) Akreditasi dilakukan untk menentukan kelayakan program dan satuan pendidikan pada jalur pendidikan formal dan nonformal pada setiap jenjang dan jenis pendidikan; Ayat (2) Akreditasi terhadap program dan satuan pendidikan dliakukan oleh lembaga mandiri yang berwenang sebagai bentuk akuntabilitas publik; dan Ayat (3) Akreditasi di lakukan atas dasar kriteria yang bersifat terbuka.

Proses akreditasi SMA dilakukan oleh BAN-SM Provinsi Kalimantan Selatan secara bertahap dimulai dari tingkat provinsi sebagai pemberi rekomendasi hinga ke tingkat nasional selaku pengambil keputusan penentuan akreditasi. proses pelaksanaan akreditasi dilaksanakan secara manual. Proses ini dilaksanakan oleh asesor maupun staf sekretariat yang bertugas menerima dan memeriksa dokumen akreditasi serta melaporkan hasil pemeriksaan dokumen dan kondisi riil di lapangan sering mengalami kendala seperti lelah, data yang hilang. Kendala-kendala tersebut dapat menjadi penyebab ketidakobjektifan proses akreditasi bahkan kemungkinan "salah nilai", sehingga untuk menghindari masalah tersebut perlu adanya alat bantu berupa sistem multiattribute decision making yang dapat mendukung kinerja BAN-SM Provinsi Kalimantan Selatan dalam melakukan penentuan akreditasi SMA, agar dapat menghasilkan keputusan yang akurat.

Beberapa penelitian yang terkait dengan multiattribute decision making penentuan akreditasi telah banyak dilakukan, diantaranya adalah penelitian [1] mengembangkan framework dalam mendukung pengambilan keputusan penentuan akreditasi perguruan tinggi di Yaman dengan teknik machine learning menggunakan metode Naïve Bayes. Penelitian [2] tentang pengembangan sistem pendukung keputusan (DSS) untuk membantu perguruan tinggi bisnis di universitas Hawaii dalam meningkatkan kualitas akreditasi perguruan tinggi. Penelitian [3] tentang pengembangan sistem pendukung peputusan dalam pemilihan Perguruan Tinggi Swasta Terbaik di Kota Medan menggunakan metode TOPSIS. Penelitian [4] tentang pengembangan sistem pendukung keputusan penentuan sekolah terbaik dikota Jambi menggunakan metode SAW.

Penelitian yang sekarang dilakukan adalah untuk mengembangkan multiattribute decision making penentuan akreditasi SMA, metode yang digunakan 
penelitian ini yaitu metode Eckenrode untuk menghitung bobot yang kriteria dan metode DIA untuk menghitung rangking alternatif keputusan.

\section{METODOLOGI PENELITIAN}

Metodologi yang dilakukan dalam penelitian ini menggunakan wawancara, pengumpulan dokumen dan studi pustaka. Wawancara dilakukan untuk memperoleh informasi terkait dengan proses penentuan akreditasi SMA, wawancara dilakukan dengan pihak Badan Akreditasi Nasionla (BAN-SM) Provinsi Kalimatan Selatan. Pengumpulan dokumen dilakukan untuk mendapatkan dokumen-dokumen input dan output serta dokumen pendukung penelitian. Dokumen yang digunakan pada penelitian ini seperti dokumen proses prosedur dan penilaian akreditasi. Studi pustaka dilakukan guna mencari referensi penelitian terdahulu yang terkaitan dengan penelitian yang sekarang dilakukan dan untuk menentukan penerapan metode yang akan digunakan dalam penelitian.

\subsection{Data Altenatif, Kriteria dan Bobot}

Membangun sebuah model multiattribute decision making diperlukan sebuah alternatif, kriteria dan bobot, dari hasil wawancara dan studi dokumentasi ke kantor Badan Akreditasi Nasionla (BAN-SM) Provinsi Kalimatan Selatan diperoleh data alternatif, kriteria dan bobot sebagai berikut:

\begin{tabular}{cl}
\multicolumn{2}{c}{ Tabel 1 Alternatif } \\
\hline Kode & \multicolumn{1}{c}{ Alternatif } \\
Altenatif & \\
\hline A1 & Peringkat akreditasi A (Unggul) \\
A2 & Peringkat akreditasi B (Baik) \\
A3 & Peringkat akreditasi C (Cukup) \\
A4 & Peringkat akreditasi D (Kurang) \\
A5 & Peringkat akreditasi E (Sangat Kurang) \\
\hline
\end{tabular}

Tabel 2 Kriteria

\begin{tabular}{clc}
\hline $\begin{array}{c}\text { Kode } \\
\text { Kriteria }\end{array}$ & \multicolumn{1}{c}{ Nama Kriteria } & $\begin{array}{c}\text { Bobot } \\
\text { Kriteria }\end{array}$ \\
\hline C1 & Standar Isi & $12 \%$ \\
C2 & Standar Proses & $14 \%$ \\
C3 & Standar Kompetensi Lulusan & $15 \%$ \\
C4 & Standar Pendidik Dan Tenaga Kependidikan & $15 \%$ \\
C5 & Standar Sarana Dan Prasarana & $14 \%$ \\
C6 & Standar Pengelolaan & $10 \%$ \\
C7 & Standar Pembiayaan & $10 \%$ \\
C8 & Standar Penilaian Pendidikan & $10 \%$ \\
\hline
\end{tabular}




\subsection{Metode Eckenrode}

Metode Eckenrode digunakan untuk melakukan proses normalisasi nilai bobot yang akan digunakan untuk menentukan derajat kepentingan dari setiap kriteria dalam pengambilan keputusan. Langkah-langkah perhitungan bobot menggunakan metode Eckenrode adalah sebagai berikut. Formula untuk penentuan nilai bobot [5] yaitu:

$$
w_{i}=\frac{\sum_{j=1}^{n} \lambda_{e j}}{\sum_{e=1}^{k} \lambda_{e j} \sum_{j=1}^{n} \lambda_{e}}
$$

Dimana $\lambda$ ej $=$ nilai tujuan/kriteria ke $\lambda$ oleh ahli ke $\mathrm{j}, \mathrm{n}=$ jumlah ahli, $w_{i}=$ nilai bobot kriteria

\subsection{Metode DIA}

Metode The Distance to the Ideal Alternative (DIA) merupakan metode untuk penyelesaian multiatribute decision making berdasarkan suatu jarak ideal alternatif dengan memilih alternatif yang terbaik. Tahapan penyelesaian metode DIA adalah berikut ini [6]:

a. Membuat matrik keputusan : matrik keputusan yang dibuat adalah sebagai berikut :

$$
D=\left(\begin{array}{ccccc}
X_{11} & X_{12} & \ldots & \ldots & X_{1 n} \\
X_{21} & X_{22} & \ldots & \ldots & X_{2 n} \\
\ldots & \ldots & \ldots & \ldots & \ldots \\
X_{31} & X_{32} & \ldots & \ldots & X_{n n}
\end{array}\right)
$$

Dimana setiap $d_{i j}$ merupakan matrik keputusan terhadap alternatif $A_{i}$ dengan kriteria $C_{j}$

b. Membuat matrik keputusan yang ternormalisasi, proses normalisasi dari nilai $r_{i j}$ dilakukan dengan menggunakan persamaan berikut:

$$
r_{i j}=\frac{d_{i j}}{\sqrt{\sum_{i=1}^{m} d_{i j}^{2}}}, i=1, \ldots, m, j=1, \ldots, n
$$

c. Membuat matrik keputusan ternormalisasi terbobot. Suaut matrik keputusa ternormalisasi terbobot $\mathrm{v}_{\mathrm{ij}}$ dihitung dengan persamaan berikut:

$$
v_{i j}=W_{i}^{*} r_{i j} \text { dimana } \sum_{i=1}^{m} W_{i}=1
$$

d. Menghitung nilai solusi ideal positif dan solusi ideal negatif. Solusi ideal dinotasikan A+ dan solusi ideal negatif dinotasikan A-. Menghitung nilai solusi ideal positif dan negatif menggunakan persamaan berikut :

$$
\begin{aligned}
A^{*} & =\left[V_{1}^{*}, \ldots, V_{m}^{*}\right] \text { dan } A^{-}=\left[V_{1}^{-}, \ldots, V_{m}^{-}\right] \\
V_{i}^{*} & =\max \left\{v_{i j}, j=1, \ldots, n\right\}
\end{aligned}
$$




$$
\begin{aligned}
& V_{i}^{-}=\min \left\{v_{i j}, j=1, \ldots, n\right\} \\
& V_{i}^{*}=\min \left\{v_{i j}, j=1, \ldots, n\right\} \\
& V_{i}^{-}=\max \left\{v_{i j}, j=1, \ldots, n\right\}
\end{aligned}
$$

e. Menentukan jarak ke atribut positif dan negatif dengan manhattan distance :

$$
\begin{aligned}
& D_{j}^{*}=\sum_{i=1}^{m}\left|V_{i}^{*}-V_{j i}^{-}\right|, j=1, \ldots, n \\
& D_{j}^{-}=\sum_{i=1}^{m}\left|V_{j i}-V_{i}^{-}\right|, j=1, \ldots, n
\end{aligned}
$$

f. Menhitung nilai ideal alternatif positif (PIA) dengan $\mathrm{D}^{*}$ adalah minimum dan $\mathrm{D}^{-}$ adalah maksimum, menggunakan persamaan berikut :

$$
P I A=\left\{\max \left(D_{j}^{*}\right), \max \left(D_{j}^{-}\right)\right\}, j=1, \ldots, n
$$

g. Menentukan jarak dari alternatif PIA

$$
R_{j}=\sqrt{\left(D_{j}^{*}-\min \left(D_{j}^{*}\right)\right)^{2}-\left(D_{j}^{-}-\max \left(D_{j}^{-}\right)\right)^{2}}
$$

Nilai Rj dari peringkat terbesar menunjukkan alternatif yang dipilih.

\section{HASIL DAN PEMBAHASAN}

Pemgembangan multiattribute deicision making untuk menentukan akreditasi SMA menggunakan metode Eckenrode dan DIA. Metode Eckenrode digunakan untuk menghitung nilai bobot dan DIA digunakan untuk menghitung nilai rating kecocokan alternatif dan kriteria.

Tahapan penyelesaikan multiattribute deicision making terlebih dahulu dibuat sebuah matrik rating kinerja $X$ terhadap alternatif $A=(i=1,2, \ldots, m)$ dimana $m$ adalah banyaknya suatu alternatif berjumlah $m$, dengan kriteria $C=(j=1,2, \ldots, n)$ dimana $\mathrm{n}$ adalah banyaknya suatu kriteria berjumlah $\mathrm{n}$. Tabel 3 Matrik rating kinerja secara umum.

Tabel 3 Matrik Rating Kinerja Secara Umum

\begin{tabular}{rcccc}
\hline \multirow{2}{*}{ Alternatif } & \multicolumn{5}{c}{ Kriteria } \\
\cline { 2 - 5 } & $\mathrm{C}_{1}$ & $\mathrm{C}_{2}$ & $\ldots$. & $\mathrm{C}_{5}$ \\
\hline $\mathrm{A}_{1}$ & $\mathrm{X}_{11}$ & $\mathrm{X}_{12}$ & $\ldots$. & $\mathrm{X}_{1 \mathrm{n}}$ \\
$\mathrm{A}_{2}$ & $\mathrm{X}_{21}$ & $\mathrm{X}_{22}$ & $\ldots$. & $\mathrm{X}_{2 \mathrm{n}}$ \\
$\ldots$ & $\ldots$. & $\ldots$. & $\ldots$. & $\ldots$. \\
$\mathrm{Am}$ & $\mathrm{X}_{\mathrm{m} 1}$ & $\mathrm{X}_{\mathrm{m} 2}$ & $\ldots$. & $\mathrm{X}_{\mathrm{mn}}$ \\
\hline
\end{tabular}


Dari Tabel 3 sebagai contoh jika ada suatu ada SMA akan mengajukan dokumen akreditasi, maka dengan mengacatu pada Tabel 1 bahwa Alternatif $A_{1}$ adalah Akreditasi_A, A2 adalah Akreditasi_B dan $\mathrm{A}_{3}$ adalah Akreditasi_C dan seterusnya dan Berdasarkan Tabel 2 ada 8 kriteria yaitu $\mathrm{C}_{1}$ adalah Standar Isi, $\mathrm{C}_{2}$ adalah Standar Proses, $\mathrm{C}_{3}$ adalah Standar Kompetensi Lulusan, $\mathrm{C}_{4}$ adalah Standar Pendidik Dan Tenaga Kependidikan, $\mathrm{C}_{5}$ adalah Standar Sarana dan Prasarana, $\mathrm{C}_{6}$ adalah Standar Pengelolaan, $\mathrm{C}_{7}$ adalah Standar Pembiayaan, dan $\mathrm{C}_{8}$ adalah Standar Penilaian Pendidikan, sehingga Tabel 4 menunjukkan matrik rating kinerja alternatif terhadap kriteria.

Tabel 4 Matrik Rating Kinerja Alternatif terhadap Kriteria

\begin{tabular}{lcccc}
\hline \multirow{2}{*}{ Alternatif } & \multicolumn{4}{c}{ Kriteria } \\
\cline { 2 - 5 } & Standa isi $\left(\mathrm{C}_{1}\right)$ & $\begin{array}{c}\text { Standar } \\
\text { Prose }\left(\mathrm{C}_{2}\right)\end{array}$ & $\cdots$ & $\begin{array}{c}\text { Standar Penilaian } \\
\text { Pendidikan }\left(\mathrm{C}_{8}\right)\end{array}$ \\
\hline $\mathrm{A}_{1}=$ Akreditasi_A & $\mathrm{X}_{11}$ & $\mathrm{X}_{12}$ & $\ldots$ & $\mathrm{X}_{111}$ \\
$\mathrm{~A}_{2}=$ Akreditasi_B & $\ldots$ & $\ldots$ & $\ldots$ & $\ldots$ \\
$\mathrm{A}_{3}=$ Akreditasi_C & $\mathrm{X}_{21}$ & $\mathrm{X}_{32}$ & $\ldots$ & $\mathrm{X}_{311}$ \\
\hline
\end{tabular}

Selanjutanya membangung sebuat matrik keputusan alternatif akreditasi berdasarkan rating kecocokan dari setiap alternatif pada setiap kriteria yang dapat dilihat pada Tabel 5.

Tabel 5. Rating kecocokan dari setiap alternatif pada setiap kriteria

\begin{tabular}{lllllllll}
\hline Altetnatif & \multicolumn{8}{c}{ Kriteria } \\
\cline { 2 - 9 } & $\mathrm{C}_{1}$ & $\mathrm{C}_{2}$ & $\mathrm{C}_{3}$ & $\mathrm{C}_{4}$ & $\mathrm{C}_{5}$ & $\mathrm{C}_{6}$ & $\mathrm{C}_{7}$ & $\mathrm{C}_{8}$ \\
\hline $\mathrm{A} 1$ & 91 & 91 & 91 & 91 & 91 & 91 & 91 & 91 \\
$\mathrm{~A} 2$ & 81 & 81 & 81 & 81 & 81 & 81 & 81 & 81 \\
$\mathrm{~A} 3$ & 71 & 71 & 71 & 71 & 71 & 71 & 71 & 71 \\
$\mathrm{~A} 4$ & 70 & 70 & 70 & 70 & 70 & 70 & 70 & 70 \\
$\mathrm{~A} 5$ & 60 & 60 & 60 & 60 & 61 & 60 & 60 & 60 \\
\hline
\end{tabular}

Berdasarkan Tabel 5 tersebut di atas, ada dua tahapan untuk menyelesaikan proses multiattribute deicision making pada penelitian ini, yaitu: 1). tahapan menghitung nilai bobot dengan metode Eckenrode; dan 2). tahapan menghitung nilai rangking alternatif keputusan dengan metode DIA. Tahapan ini akan diuraikan pada sebagai berikut:

\subsection{Tahapan Pembobotan dengan Metode Eckenrode}

Berdasarkan Tabel 2 ada delapan kriteria yang diberikan nilai bobotnya berdasarkan tingkat kepentingan kriteria. Misalnya pada kasus ini, kriteria $\mathrm{C}_{1}$ adalah "Standar isi" diberikan skor 12. Kriteria $\mathrm{C}_{2}$ adalah "Standar Proses" diberikan skor 14. Dengan cara yang sama dilakukan untuk pemberian nilai bobot kriteria yang lain. Adapun proses perhitungan nilai bobot menggunakan metode Eckenrode sebagai berikut. 
a. Dengan mengacu Tabel 2 maka dilakukan pemberian nilai bobot kriteria yang dapat dilihat pada Tabel 6.

Tabel 6 Nilai bobot kriteria

\begin{tabular}{ccccccccc}
\hline Kriteria & C1 & C2 & C3 & C4 & C5 & C6 & C7 & C8 \\
\hline $\begin{array}{c}\text { Nilai } \\
\text { Bobot }\end{array}$ & 12 & 14 & 15 & 15 & 14 & 10 & 10 & 10 \\
\hline
\end{tabular}

b. Berdasarkan data Tabel 6 dilakukan proses perhitungan menggunakan persamaan 1, maka dihasilkan perhitungan bobot kriteria sebagai berikut :

Tabel 7 Hasil perhitungan bobot kriteria dengan metode Eckenrode

\begin{tabular}{ccccccccc}
\hline Kriteria & C1 & C2 & C3 & C4 & C5 & C6 & C7 & C8 \\
\hline $\begin{array}{c}\text { Nilai } \\
\text { Bobot }\end{array}$ & 0.12 & 0.14 & 0.15 & 0.15 & 0.14 & 0.10 & 0.10 & 0.10 \\
\hline
\end{tabular}

Misal Sebuat SMA mengajukan dokumen akreditasi dengan nilai bobot kriteria sebagai berikut:

$\begin{array}{ll}\text { Standar isi } & 66 \\ \text { Standar proses } & 78 \\ \text { Standar kompetensi lulusan } & 82 \\ \text { Standar pendidik dan tenaga kependidikan } & 90 \\ \text { Standar sarana dan prasarana } & 88 \\ \text { Standar pengelolaan } & 91 \\ \text { Standar pembiayaan } & 85 \\ \text { Standar penilaian pendidikan } & 86\end{array}$

Nilai bobot kriteria SMA akan di normalisasi dengan nilai bobot prioritas kriteria yang telah diperoleh melalui perhitungan metode Eckenrode

$\begin{array}{ll}\text { Standar isi } & =(66+0.12 / 2=33.06 \\ \text { Standar proses } & =(78+0.14) / 2=39.07 \\ \text { Standar kompetensi lulusan } & =(82 /+0.15) 2=41.08 \\ \text { Standar pendidik dan tenaga kependidikan } & =(90+0.15) / 2=45.08 \\ \text { Standar sarana dan prasarana } & =(88+0.14) / 2=44.07 \\ \text { Standar pengelolaan } & =(91+0.10) / 2=45.55 \\ \text { Standar pembiayaan } & =(85+0.10) / 2=42.55 \\ \text { Standar penilaian pendidikan } & =(86+0.10) / 2=43.05\end{array}$

Hasil dari perhitungan nilai bobot kriteria tersebut digunakan untuk proses perangkingan alternatif keputusan pada tahapan perhitungan nilai matrik ternormalisasi terbobot pada metode DIA. 


\subsection{Tahapan Perangkingan Alternatif Keputusan dengan Metode DIA}

Berdasarkan Tabel 5 Rating kecocokan dari setiap alternatif pada setiap kriteria, bahwa dari nilai Rating kecocokan dari setiap alternatif pada setiap kriteria tersebut kemudian dilakukan proses perangkingan alternatif keputusan. Pada proses perangkingan alternatif keputusan ini penyelesaiannya menggunakan metode DIA yang diintergrasikan dengan perhitungan nilai bobot kriteria dengan metode Eckenrode. Adapun langkah-langkah proses perangkingan alternatif keputusan adalah sebagai berikut :

a. Menghitung nilai normalisasi menggunakan persamaan (3). Perhitungan ini menggunakan data pada tabel 5 yaitu sebagai berikut:

1) $91 / \mathrm{SQRT}\left(91^{\wedge} 2\right)+\left(81^{\wedge} 2\right)+\left(71^{\wedge} 2\right)+\left(70^{\wedge} 2\right)+\left(60^{\wedge} 2\right)=0.5401$

2) $81 / \mathrm{SQRT}\left(91^{\wedge} 2\right)+\left(81^{\wedge} 2\right)+\left(71^{\wedge} 2\right)+\left(70^{\wedge} 2\right)+\left(60^{\wedge} 2\right)=0.4808$

3) $71 / \mathrm{SQRT}\left(91^{\wedge} 2\right)+\left(81^{\wedge} 2\right)+\left(71^{\wedge} 2\right)+\left(70^{\wedge} 2\right)+\left(60^{\wedge} 2\right)=0.4214$

4) $70 / \mathrm{SQRT}\left(91^{\wedge} 2\right)+\left(81^{\wedge} 2\right)+\left(71^{\wedge} 2\right)+\left(70^{\wedge} 2\right)+\left(60^{\wedge} 2\right)=0.4155$

5) $60 / \mathrm{SQRT}\left(91^{\wedge} 2\right)+\left(81^{\wedge} 2\right)+\left(71^{\wedge} 2\right)+\left(70^{\wedge} 2\right)+\left(60^{\wedge} 2\right)=0.3561$

Kemudian dilakukan perhitungan yang sama, untuk kriteria C2, C3, C4, C5, C6, C7 dan C8 terhadap alternatif A1, A2, A3, A4 dan A5, sehingga hasil perhitungan tersebut dapat dilihat pada Tabel 8 berikut ini:

Tabel 8. Matrik Normalisasi

\begin{tabular}{llllllll}
\hline 0.5401 & 0.5401 & 0.5401 & 0.5401 & 0.5390 & 0.5401 & 0.5401 & 0.5401 \\
\hline 0.4808 & 0.4808 & 0.4808 & 0.4808 & 0.4798 & 0.4808 & 0.4808 & 0.4808 \\
\hline 0.4214 & 0.4214 & 0.4214 & 0.4214 & 0.4205 & 0.4214 & 0.4214 & 0.4214 \\
\hline 0.4155 & 0.4155 & 0.4155 & 0.4155 & 0.4146 & 0.4155 & 0.4155 & 0.4155 \\
\hline 0.3561 & 0.3561 & 0.3561 & 0.3561 & 0.3613 & 0.3561 & 0.3561 & 0.3561 \\
\hline
\end{tabular}

b. Menghitung nilai normalisasi terbobot menggunakan persamaan (4), perhitungan ini menggunakan data pada tabel 7 dan tabel 8 yaitu sebagai berikut:
1) $0.5401 * 33.06=17.8573$
2) $0.5401 * 39.07=22.1036$
3) $10.5401 * 41.08=22.1893$
4) $10.5401 * 45.08=24.3499$

Kemudian dilakukan perhitungan yang sama, untuk kriteria C5, C6, C7 dan C8 pada Tabel 8 terhadap alternatif A1, A2, A3, A4, dan A5, sehingga hasil perhitungan tersebut dapat dilihat pada tabel 9 berikut ini:

Tabel 9. Matrik Normalisasi Terbobot

\begin{tabular}{llllllll}
\hline 17.8573 & 21.1036 & 22.1893 & 24.3498 & 23.7537 & 24.6037 & 22.9833 & 23.2533 \\
\hline 15.8949 & 18.7845 & 19.7509 & 21.6740 & 21.1434 & 21.9000 & 20.4576 & 20.6980 \\
\hline 13.9326 & 16.4654 & 17.3125 & 18.9982 & 18.5331 & 19.1963 & 17.9320 & 18.1427 \\
\hline 13.7364 & 16.2335 & 17.0687 & 18.7306 & 18.2721 & 18.9259 & 17.6794 & 17.8872 \\
\hline
\end{tabular}


\begin{tabular}{llllllll}
11.7740 & 13.9144 & 14.6303 & 16.0548 & 15.9228 & 16.2222 & 15.1538 & 15.3319 \\
\hline
\end{tabular}

c. Menentukan nilai solusi ideal positif dan solusi ideal negatif. Solusi ideal positif dan solusi ideal negatif dapat dihitung berdasarkan nilai normalisasi terbobot menggunakan persamaan (5) , perhitungan ini menggunakan data pada tabel 10 yaitu sebagai berikut:

- $\mathrm{A}+=\operatorname{Max}(17.8573,15.8949,13.9326,13.7364,11.7740)=17.8573$

- $\mathrm{A}-=\operatorname{Max}(17.8573,15.8949,13.9326,13.7364,11.7740)=11.7740$

Kemudian dilakukan perhitungan yang sama, untuk kriteria C2, C3 dan C4, sehingga hasil perhitungan tersebut dapat dilihat seperti berikut ini:

Tabel 10 Nilai solusi ideal positif dan negatif

\begin{tabular}{ccccccccc}
\hline $\mathrm{A}_{+}=$ & 17.8573 & 21.1036 & 22.1893 & 24.3498 & 23.7537 & 24.6037 & 22.9833 & 23.2533 \\
\hline $\mathrm{A}^{-}=$ & 11.7740 & 13.9144 & 14.6303 & 16.0548 & 15.9228 & 16.2222 & 15.1538 & 15.3319 \\
\hline
\end{tabular}

d. Menghitung jarak antara setiap alternatif dengan solusi ideal positif dan solusi ideal negatif menggunakan persamaan (6) dan (7), perhitungan ini menggunakan data pada Tabel 9 dan Tabel 10 yaitu sebagai berikut:

- Untuk mencari nilai D+ maka :

$(17.8573-17.8573)+(21.1036-21.1036)+(22.1893-22.1893)+(24.3498-$

$24.3498)+(23.7537-23.7537)+24.6037-24.6037)+(22.9833-$

$22.9833)+(23.2533-23.2533)=0.0000$

- Untuk mencari nilai D- maka :

$(17.8573-11.7740)+(21.1036-13.9144)+(22.1893-14.6303)+(24.3498-$

$16.0548)+(23.7537-15.9228)+(24.6037-16.2222)+(22.9833-$

$15.1538)+(23.2533-15.3319)=61.0897$

Kemudian dilakukan perhitungan yang sama, sehingga hasil perhitungan tersebut dapat dilihat seperti berikut ini:

Tabel 11 Hasil Perhitungan Jarak

\begin{tabular}{cc}
$\mathrm{D}^{*}$ & $\mathrm{D}-$ \\
\hline 0.0000 & 61.0897 \\
\hline 19.7905 & 41.2991 \\
\hline 39.5811 & 21.5086 \\
\hline 41.5601 & 19.5295 \\
\hline 61.0897 & 0.0000 \\
\hline
\end{tabular}

e. Menentukan nilai ideal alternatif positif (PIA) menggunakan persamaan (8), perhitungan ini menggunakan data D+ dan D-yaitu sebagai berikut:

1) $\min (0.0000 ; 19.7905 ; 39.5811 ; 41.5601 ; 61.0897)$

2) $\max (61.0897 ; 41.2991 ; 21.5086 ; 19.5295 ; 0.0000)$ 
sehingga hasil perhitungan tersebut dapat dilihat seperti berikut ini:

$$
P I A=0.0000 \quad 61.0897
$$

f. Hitung jarak alternatif PIA menggunakan persamaan (9), perhitungan ini menggunakan data $\mathrm{D}+, \mathrm{D}-$ dan PIA, yaitu sebagai berikut :

1) SQRT $\left((0.0000-61.0897)^{\wedge} 2+(61.0897-0,0000)^{\wedge} 2\right)=86.3938$

2) SQRT $\left((19.7905-61.0897)^{\wedge} 2+(41.2991-0,0000)^{\wedge} 2\right)=58.4058$

3) SQRT $\left((39.5811-61.0897)^{\wedge} 2+(21.5086-0,0000)^{\wedge} 2\right)=30.4177$

4) $\operatorname{SQRT}\left((41.5601-61.0897)^{\wedge} 2+(19.5295-0,0000)^{\wedge} 2\right)=27.6189$

5) $\operatorname{SQRT}\left((61.0897-61.0897)^{\wedge} 2+(0.0000-0,0000)^{\wedge} 2\right)=0.0000$

Sehingga hasil perhitungan tersebut dapat dilihat seperti berikut ini:

$$
\begin{array}{rr}
R 1 & 86.3938 \\
R 2 & 58.4058 \\
R 3 & 30.4177 \\
R 4 & 27.6189 \\
R 5 & 0.0000
\end{array}
$$

Alternatif yang dipilih sebagai alternatif keputusan adalah nilai tertinggi = 86.3938 adalah Akreditasi A.

Berdasarkan hasil pengujian dengan menggunakan 50 sampel data yang diperoleh dari BAN-SM Provinsi Kalimantan Selatan, maka diperoleh hasil pengujian seperti pada Tabel 12 .

Tabel 12: Hasil Pengujian

\begin{tabular}{ccccccc}
\hline Kenyataan & \multicolumn{7}{c}{ MADM (Akreditasi) } & Jumlah \\
\cline { 2 - 5 } & A & B & C & D & E & \\
\hline A & 11 & & & & & 11 \\
\hline B & & 25 & & & & 25 \\
\hline C & \multicolumn{7}{c}{10} & & & 10 \\
\hline D & & & & 1 & 1 & 2 \\
\hline E & & & & & 50 \\
\hline Total & & & & & & \\
\hline
\end{tabular}

Berdasarkan Tabel 12 tersebut kemudian dilakukan proses perhitungan menggunakan confusion matrix untuk menentukan nilai sensitivity dan accuracy. Berikut Tabel 13 Hasil evaluasi menggunakan confusion matrix 
Tabel 13. Hasil Perhitungan confusion matrix

\begin{tabular}{ccc}
\hline Uji & \multicolumn{2}{c}{ Nilai } \\
\cline { 2 - 3 } Metode & Sensitivity & Accuracy \\
\hline SPK & $97 \%$ & $98 \%$ \\
\hline
\end{tabular}

Berdasarkan Tabel 13 hasil perhitungan dengan confusion matrix menunjukkan nilai sensitivity 97\%, dan nilai accuracy 98\%., dapat dilihat dalam bentuk grafik pada Gambar 2

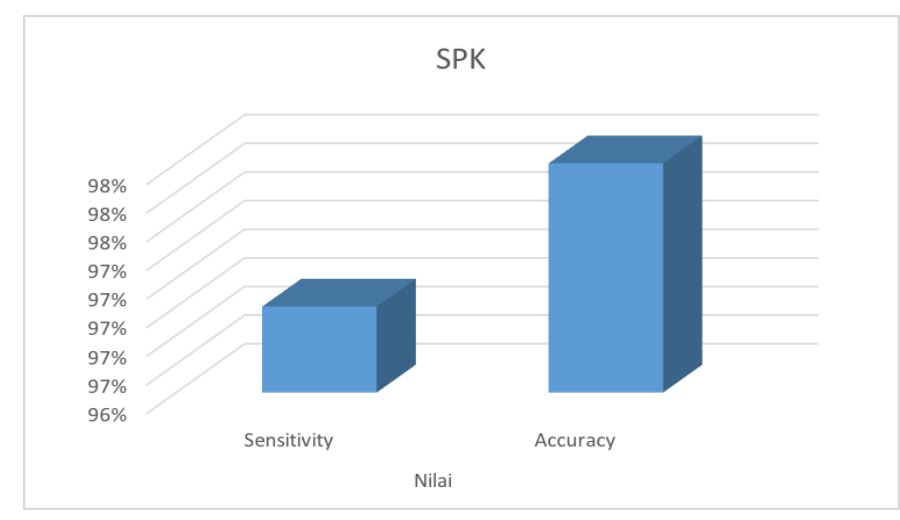

Gambar 2: Grafik Hasil Perhitungan dengan confusion matrix

Hasil perhitungan dengan confusion matrix pada Tabel 13 dan Gambar 2 bahwa sistem pendukung keputusan menggunaka metode Eckenrode dan DIA menunjukkan dengan nilai sensitivity (kemampuan dalam menentukan rekomendasi akreditasi dengan hasil positif dan benar terakreditasi) sebesar 97\%, dan nilai accuracy (ketepatan dalam menentukan rekomendasi akreditasi benar terakreditasi) sebesar $98 \%$.

\section{SIMPULAN}

Penelitian ini dilakukan dalam rangka untuk menyelesaikan masalah penentuan peringkat akreditasi SMA dengan cara mengembangkan multiattribute deicision making, sedangkan metode yang digunakan adalah metode Eckenrode untuk menghitung nilai bobot dan metode DIA untuk menghitung proses perangkingan, dalam proses perangkingan pada tahapan normalisasi terbobot, hasil dari proses perhitungan bobot dengan metode Eckenrode digunakan dalam tahapan normalisasi terbobot pada metode DIA. Hasil pengujian dnengam menggunakan 50 data bahawa penelitian ini menunjukan nilai akurasi sebesar $98 \%$ dan nilai sensitivitas sebesar 97\%, Hasil penelitian ini menunjukkan bahwa multiattribute deicision making menggunakan metode Eckenrode dan DIA dapat diterapkan dalam menentukan peringkat akreditasi SMA. 


\section{DAFTAR PUSTAKA}

[1] Fatek Saeed, Anurag Dixit, "A decision support system approach for accreditation \& quality assurance council at higher education institutions in Yemen", IEEE 3rd International Conference on MOOCs, Innovation and Technology in Education (MITE), Vol.3 No. 1, pp.163-168, Oct 2015. DOI: 10.1109/MITE.2015.7375308

[2] David Farwell, William Remus, "A Decision Support System for Business School Accreditation", The Journal of Data Education, Vol X, No.X, pp 10-112, Feb 2016. DOI: 10.1080/00220310.1985.11646332.

[3] Yuyun D.L, Mardiana M, "Decision Support System For Determining the Best College High Private Using Topsis Method", Sinkron, Vol.4, No. 2, pp. 27-33, Sep 2019, DOI : 10.33395/sinkron.v4i2.10235.

[4] Ibrahim, Surya," The Implementation of Simple Additive Weighting (SAW) Method in Decision Support System for the Best School Selection in Jambi", ICASMI 2018 IOP Publishing Conf. Series: Journal of Physics: Conf. Series1338, Vol. X, No.X, pp. 1-7, 2019, DOI: 10.1088/17426596/1338/1/0120541.

[5] Saaty, T.L.. “Decision Making For Leaders. Forth edition”, University of Pittsburgh: RWS Publication. 2001.

[6] Mohamed Lahby, "Leghris Cherkaoui and Abdellah Adib, 2012,New Multi Access Selection Method Based on Mahalanobis Distance", Applied Mathematical Sciences, Vol. 6, No. 55, pp. 2745 - 2760, 2012. 